\title{
Efficacy of Stereotactic Body Radiation Therapy in Patients With Pd-1 Inhibitor-transarterial Chemoembolization Refractory Intermediate-stage Hepatocellular Carcinoma: a Retrospective Controlled Study
}

\section{Yan-Jun Xiang}

Eastern Hepatobiliary Surgery Hospital

\section{Kang Wang}

Eastern Hepatobiliary Surgery Hospital

\section{Yi-Tao Zheng}

The First Affiliated Hospital of Wenzhou Medical University

\section{Shuang Feng}

Eastern Hepatobiliary Surgery Hospital

Hong-Ming Yu

Eastern Hepatobiliary Surgery Hospital

Xiao-Wei Li

Eastern Hepatobiliary Surgery Hospital

\section{Xi Cheng}

Eastern Hepatobiliary Surgery Hospital

\section{Yu-Qiang Cheng}

Eastern Hepatobiliary Surgery Hospital

Wei-Jun Wang

Eastern Hepatobiliary Surgery Hospital

Jin-Kai Feng

Eastern Hepatobiliary Surgery Hospital

\section{Ying-Yi Qin}

Second Military Medical University

\section{Li-Ping Zhou}

Eastern Hepatobiliary Surgery Hospital

\section{Yan Meng}

Eastern Hepatobiliary Surgery Hospital Jian Zhai

Eastern Hepatobiliary Surgery Hospital 


\section{Yun-Feng Shan}

The First Affiliated Hospital of Wenzhou Medical University

\section{Shu-Qun Cheng ( $\square$ chengshuqun@aliyun.com )}

Department of Hepatic Surgery VI, Eastern Hepatobiliary Surgery Hospital, Second Military Medical University, Shanghai https://orcid.org/0000-0001-6760-7470

\section{Research Article}

Keywords: Hepatocellular carcinoma, Stereotactic body radiation therapy, Transarterial chemoembolization refractory, Toripalimab, Sintilimab, Combination therapy, Overall survival, Progression-free survival, Tumor response, Adverse events

Posted Date: October 25th, 2021

DOl: https://doi.org/10.21203/rs.3.rs-958058/v1

License: (c) (1) This work is licensed under a Creative Commons Attribution 4.0 International License. Read Full License 


\section{Abstract}

\section{Introduction:}

Transarterial chemoembolization (TACE) combined with PD-1 inhibitor is a novel and effective combination therapy. However, there is currently a gap in subsequent treatment when patients are diagnosed with PD-1 inhibitors-TACE refractoriness.

\section{Methods:}

This retrospective cohort study included enrolled patients with intermediate stage HCC who were diagnosed with PD-1 inhibitor-TACE refractoriness between January 2019 and December 2020 in the Eastern Hepatobiliary Surgery Hospital and the First Affiliated Hospital of Wenzhou Medical University. They were divided into two cohorts, (1) those who switched from TACE combined with PD-1 to stereotactic body radiation therapy (SBRT) combined with PD-1 and (2) those who continued TACE combined with PD-1. Progression free survival (PFS), overall survival (OS), and tumor response were assessed in both groups after refractory to PD-1 inhibitors combined with TACE.

Results: Of the seventy-six patients included in this study, the median PFS was 19.6 months in the SBRT group ( $n=31)$ and 10.1 month in the TACE group $(n=45, p<0.05)$. The SBRT group also had a significant higher OS than the TACE group ( $p<0.05)$. Objective response rate (ORR) and disease control rate (DCR) were also better in the SBRT group (ORR, 71.0\% vs. $15.6 \%, \mathrm{OR}=8.483,95 \% \mathrm{Cl} 3.319-21.680, \mathrm{P}<0.001$; DCR, $80.6 \%$ vs. $31.1 \%$, OR=9.226, $95 \% \mathrm{Cl} 3.096-27.493, \mathrm{P}<0.001)$.

Conclusions: SBRT combined with PD-1 inhibitor improves PFS and OS in patients refractory to PD-1 inhibitor combined with TACE. Therefore, SBRT is recommended in case of failure of treatment with PD-1 inhibitors combined with TACE.

\section{Introduction}

Hepatocellular carcinoma (HCC) is the most common primary liver cancer and the fourth leading cause of cancer-related death worldwide[1]. Since patients with early-stage HCC are usually asymptomatic, approximately half of HCC patients are diagnosed at intermediate to advanced stages and cannot undergo radical treatment[2-5].

For patients with intermediate stage HCC, TACE is recommended as the standard treatment by many guidelines[6-9]. However, the efficacy of TACE alone is limited and some patients would be diagnosed as TACE refractory[10, 11]. Most guidelines recommend starting systemic therapy as soon as TACE refractoriness appears (defined as failure to achieve an objective response after two procedures) $[6,8,9]$. As a new systemic therapeutic drug, PD-1 inhibitor has synergistic effect with TACE[12,13]. The ORR of patients who received TACE combined with PD-1 inhibitor therapy was 47.1\%[14]. In other words, more 
than half of the patients did not achieve an effective tumor response, and there is currently a lack of relevant reports regarding subsequent therapies for this subset of patients.

Stereotactic body radiotherapy (SBRT) is a newer treatment modality with evidence of promising local control for patients with HCC[15-17]. And for early and intermediate stage HCC patients, SBRT is a safe alternative to TACE and provides no inferior or even better local control and OS than TACE[18, 19].

Based on the above literature, we speculated that SBRT might be a reasonable alternative for patients with PD-1 inhibitor-TACE refractory. While there are no relevant reports available so far. We conducted this retrospective study to evaluate the efficacy and safety of SBRT in patients with PD-1 inhibitor-TACE refractory intermediate-stage hepatocellular carcinoma.

\section{Methods}

\section{Patients}

A retrospective study was conducted on consecutive HCC patients at the Eastern Hepatobiliary Surgery Hospital and the First Affiliated Hospital of Wenzhou Medical University from 2019 to 2020. This study was approved by the Institutional Ethics Committee of the Eastern Hepatobiliary Surgery Hospital of the main center. As patient identities were anonymized, the requirement for informed consent was waived by the Ethics Committees.

The inclusion criteria were patients with: (1) HCC diagnosed by histopathology, computed tomography (CT) or magnetic resonance imaging (MRI), (2) good liver function (Child-Pugh A or B7, score <= 7), (3) BCLC stage B, (4) received TACE combined with PD-1 inhibitor therapy, (5) PD-1 inhibitor refractoriness (defined as tumors that did not achieve an objective response as assessed by modified Response Evaluation Criteria in Solid Tumor (mRECIST) after 4 cycles of PD-1 inhibitor therapy), and (6) TACErefractoriness. The exclusion criteria were patients with (1) previous other locoregional or systemic therapy, (2) recurrent HCC, (3) a history of other cancers, and (4) incomplete clinical data.

\section{TACE and SBRT}

TACE was performed as previously described[20]. Briefly, the tumor feeding artery was first identified by angiography, and after cannulation of the hepatic artery, doxorubicin hydrochloride, pirarubicin and lipiodol were injected through the catheter. Post TACE evaluation and follow-up were performed every 6-8 weeks.

SBRT was performed by CyberKnife ${ }^{\circledR}$ (Accuriy Cyber knife, VSI), with a total of $24-45$ Gy in 3-5 fractions. The patients who received SBRT were first implanted with at least 3 gold fiducials inside or adjacent to the tumor under CT (Philips Brilliance CT Big Bore Oncology) guidance, and the gold fiducials were relatively stable and immobile after seven days, with localization simulated under $\mathrm{CT}$. The images are subsequently transferred to the treatment planning system (TPS), and the target area was then delineated by a radiologist. A 2-5 mm marginal expansion of the gross tumor volume (defined as 
radiologically evident gross disease) formed the planning target volume. And the physiatrist makes the treatment plan while defining normal tissue dose ranges. Dose constraints for organs at risk refer to the American Association of Physicists in Medicine guidelines in AAPM Task Group 101[21].

\section{PD-1 inhibitor}

All included patient patients were treated with PD-1 inhibitors within 7 days after the first TACE. PD-1 inhibitors included toripalimab (72.4\%) and sintilimab (27.6\%) (Supplementary Table 1).

Teriparatuzumab, 3mg/kg, by body weight, every 2 weeks; Sintilimab, $200 \mathrm{mg}$ every three weeks. The specific doses and protocols used were strictly in accordance with the instructions for use. And the PD-1 inhibitors are all administered intravenously, into which low-grade infusion reactions occur, to reduce drip plasticity or suspend dosing, when symptoms resolve and resume medication and close observation. PD1 inhibitors were continued until intolerable toxicity occurred.

\section{Follow-up and assessment}

All patients were followed up in the outpatient clinic every 1-3 months. At each follow-up visit, there were routine history taking physical examination, laboratory blood tests, and abdominal ultrasound or enhanced CT/MRI. The primary end point of this study was PFS, which was defined as the time from the first locoregional treatment after being diagnosed as PD-1 inhibitor-TACE refractory to tumor progression or death due to any cause. Assessment of tumor progression was based on the mRECIST. Overall survival (OS) was defined as the time from the first locoregional treatment after being diagnosed as PD-1 inhibitor-TACE refractory to death due to any cause or the recent follow-up.

Treatment-related adverse events (TRAEs) were obtained from clinic visit records or medical records and evaluated according to the criteria of the Common Terminology Criteria for Adverse Events (CTCAE, version 5.0). If multiple instances of the same toxicity occurred, the highest grade for each patient of a given category was adopted.

\section{Statistical analysis}

All clinical data were analyzed using IBM SPSS Statistics 23 or R 4.0 software (http://www.r-project.org/). The $\chi 2$ test or Fisher exact test was used to compare variables. The Student's t-test was used to compare continuous variables and the $\chi 2$ test or Fisher exact test was used to compare categorical variables. Survival curves were calculated using the Kaplan-Meier method and compared using the log-rank test. Hazard ratio (HR) was calculated by Cox regression models. And odd ratio (OR) was calculated by logistics regression models. $P<0.05$ was defined as a significant difference.

\section{Results}

\section{Patient characteristics and treatments}

A Flow diagram for the present study is shown in Figure 1. Of 76 patients at the Eastern Hepatobiliary Surgery Hospital and the First Affiliated Hospital of Wenzhou Medical University with complete clinic and 
follow-up data, 45 (59.2\%) patients continued TACE combined with PD-1 inhibitor therapy and 31 (47.3\%) switched SBRT combined with PD-1 inhibitor therapy. Table 1 summarizes the baseline features of these patients. There were no significant differences at baseline between the two groups, including age, gender, HBsAg, maximum tumor size, tumor number, alpha-fetoprotein concentration (AFP), Des-gamma-carboxy prothrombin (DCP), total bilirubin (TB), albumin, albumin-bilirubin grade, prothrombin time (PT), glucose, creatinine and Platelet. 
Table 1

Baseline Characteristics of Study Patients

\begin{tabular}{|c|c|c|c|}
\hline Characteristics & $\begin{array}{l}\text { TACE } \\
(n=45)\end{array}$ & $\begin{array}{l}\text { SBRT } \\
(n=31)\end{array}$ & $P$ value \\
\hline Age (year) & & & 0.945 \\
\hline$<65$ & $36(86.2)$ & $25(78.8)$ & \\
\hline$\geq 65$ & $9(13.8)$ & $6(21.2)$ & \\
\hline Gender & & & 0.168 \\
\hline Female & $6(13.8)$ & 8 (19.2) & \\
\hline Male & $39(86.2)$ & $23(80.8)$ & \\
\hline $\mathrm{HBsAg}$ & & & 0.525 \\
\hline Positive & $40(82.8)$ & $26(78.9)$ & \\
\hline Negative & 5 (17.2) & $5(21.1)$ & \\
\hline Maximum tumor size $(\mathrm{cm})$ & & & 0.275 \\
\hline$<5$ & $28(41.4)$ & $23(57.7)$ & \\
\hline$\geq 5$ & $17(58.6)$ & $8(42.3)$ & \\
\hline Tumor number & & & 0.137 \\
\hline 2 & 31 & 20 & \\
\hline 3 & 10 & 11 & \\
\hline 4 & 4 & 0 & \\
\hline AFP (ng/mL) & & & 0.610 \\
\hline$<400$ & $22(58.6)$ & 17 (61.5) & \\
\hline$\geq 400$ & $23(41.4)$ & $14(38.5)$ & \\
\hline $\mathrm{DCP}(\mathrm{mAU} / \mathrm{mL})$ & & & 0.555 \\
\hline$<2050$ & $26(65.5)$ & $20(73.1)$ & \\
\hline$\geq 2050$ & $19(34.5)$ & $11(26.9)$ & \\
\hline TB (umol/L) & & & 0.468 \\
\hline
\end{tabular}

TACE, transcatheter arterial chemoembolization; AFP, alpha-fetoprotein concentration; DCP, Desgamma-carboxy prothrombin; TB, total bilirubin; ALBI, albumin-bilirubin; PT, prothrombin time.

Triple therapy, TACE combined with PD-1 inhibitor and anti-angiogenic therapy; Doublet therapy, TACE combined with PD-1 inhibitor therapy. 


\begin{tabular}{|c|c|c|c|}
\hline Characteristics & $\begin{array}{l}\text { TACE } \\
(n=45)\end{array}$ & $\begin{array}{l}\text { SBRT } \\
(n=31)\end{array}$ & $P$ value \\
\hline$<18.8$ & 27 & 16 & \\
\hline$\geq 18.1$ & 18 & 15 & \\
\hline Albumin $(\mathrm{g} / \mathrm{L})$ & & & 0.145 \\
\hline$<35$ & 8 & 10 & \\
\hline$\geq 35$ & 37 & 21 & \\
\hline ALBI grade & & & 0.243 \\
\hline 1 & $25(55.2)$ & $13(53.9)$ & \\
\hline 2 & $20(41.4)$ & $18(46.1)$ & \\
\hline 3 & 0 & 0 & \\
\hline PT (sec) & & & 0.669 \\
\hline$<13$ & 36 & 26 & \\
\hline$\geq 13$ & 9 & 5 & \\
\hline Glucose (mmol/L) & & & 0.337 \\
\hline$<7$ & 39 & 29 & \\
\hline$\geq 7$ & 6 & 2 & \\
\hline Creatinine (umol/L, median) & 66.0 & 61.0 & 0.222 \\
\hline Platelet $\left(X 10^{9}\right.$, median $)$ & 162.0 & 174.0 & 0.625 \\
\hline \multicolumn{4}{|c|}{$\begin{array}{l}\text { TACE, transcatheter arterial chemoembolization; AFP, alpha-fetoprotein concentration; } D C P \text {, Des- } \\
\text { gamma-carboxy prothrombin; TB, total bilirubin; ALBI, albumin-bilirubin; } P T \text {, prothrombin time. }\end{array}$} \\
\hline
\end{tabular}

The median follow-up for the entire cohort was 11.5 months. Of the 76 patients enrolled in the study, 41 patients died during the study (31 in the TACE group and 10 in the SBRT group), 24 were alive (8 in the TACE group and 16 in the SBRT group), and 11 were lost to follow-up (6 in the TACE group and 5 in the SBRT group).

\section{Efficacy outcomes}

The median PFS was 19.6 months (95\% Cl 13.1-26.1) in the SBRT group and 10.1 months (95\% Cl 7.312.9) in the TACE group. The median OS was 14.1 months in the TACE group and was not reached in the 
SBRT group. The 1-year OS rate and PFS rate of SBRT group were $71.5 \%$ and $64.8 \%$, respectively, while those of TACE group were $54.2 \%$ and $40.7 \%$, respectively. SBRT significantly prolonged PFS relative to TACE (Figure 2A, HR=0.361, 95\% Cl 0.182-0.716, $\mathrm{P}<0.05$ ). Similarly, as shown in Figure 2B, SBRT significantly prolonged the OS of patients $(H R=0.375,95 \% \mathrm{Cl} 0.182-0.773, \mathrm{P}<0.05)$.

Table 2 summarizes the best tumor responses for the entire HCC patients. According to MRECIST 1.1, the ORR of $71.0 \%$ in the SBRT group was significantly higher than the $15.6 \%$ in the TACE group (OR=8.483, $95 \% \mathrm{Cl} 3.319-21.680, \mathrm{P}<0.001)$. And the disease control rate (DCR) of the SBRT group was also significantly higher than that of the TACE group $(80.6 \%$ vs. $31.1 \%$, OR=9.226, $95 \% \mathrm{Cl} 3.096-27.493, \mathrm{P}<$ 0.001).

Table 2

Best tumor response

\begin{tabular}{|llll|}
\hline & $\begin{array}{l}\text { TACE group } \\
(\mathbf{n}=\mathbf{4 5})\end{array}$ & $\begin{array}{l}\text { SBRT group } \\
(\mathbf{n = 3 1 )}\end{array}$ & Pvalue \\
\hline $\mathrm{CR}$ & 0 & $11(35.5)$ & \\
$\mathrm{PR}$ & $7(15.6)$ & $11(35.5)$ & \\
$\mathrm{SD}$ & $7(15.6)$ & $3(9.7)$ & $<0.001$ \\
\hline $\mathrm{PD}$ & $31(68.9)$ & $6(19.4)$ & $<0.001$ \\
\hline ORR & $7(15.6)$ & $22(71.0)$ & \\
\hline DCR & $14(31.1)$ & $25(80.6)$ & \\
\hline $\begin{array}{l}\text { TACE transcatheter arterial chemoembolization, SBRT stereotactic body radiation therapy, CR } \\
\text { complete response, PR partial response, SD stable disease, PD progressive disease, ORR objective } \\
\text { response rate, DCR disease control rate. }\end{array}$ & \\
\hline
\end{tabular}

\section{Safety outcomes}

According to CTCAE version 5.0, TRAEs during treatment were evaluated according to frequency and severity. Almost all patients have transient TRAEs after receiving locoregional therapies and remit spontaneously within 24 to 48 hours. Therefore, we did not analyze and discuss these transient TRAEs.

As shown in Table 3, the most common TRAEs at all levels in the TACE group were decreased platelet count (44.4\%), decreased albumin (37.8\%), and elevated AST (37.8\%). In addition, the most common grade 3/4 TRAEs was decreased platelet count (6.7\%). In the SBRT group, the most common TRAEs were increased AST (51.6\%), fatigue (48.4\%) and decreased platelet count (48.4\%), and the most common grade $3 / 4$ TRAEs were lymphopenia (9.7\%) and dysphagia (6.5\%). 
Table 3

Treatment emergent adverse events

\begin{tabular}{|c|c|c|c|c|}
\hline \multirow[t]{2}{*}{ Adverse Events } & \multicolumn{2}{|l|}{$\begin{array}{l}\text { TACE } \\
(n=45)\end{array}$} & \multicolumn{2}{|l|}{$\begin{array}{l}\text { SBRT } \\
(n=31)\end{array}$} \\
\hline & $\begin{array}{l}\text { Any grade, } \mathrm{n} \\
(\%)\end{array}$ & $\begin{array}{l}\text { Grade 3/4. n } \\
(\%)\end{array}$ & $\begin{array}{l}\text { Any grade, } \mathrm{n} \\
(\%)\end{array}$ & $\begin{array}{l}\text { Grade 3/4. n } \\
(\%)\end{array}$ \\
\hline Decreased albumin & $17(37.8)$ & 0 & $13(41.9)$ & 0 \\
\hline Dysphagia & $6(13.3)$ & 0 & $9(29.0)$ & $2(6.5)$ \\
\hline Decreased PLT & $20(44.4)$ & $3(6.7)$ & $15(48.4)$ & 0 \\
\hline Elevated AST & $17(37.8)$ & $2(4.4)$ & $16(51.6)$ & $2(6.5)$ \\
\hline Elevated ALT & $13(26.9)$ & $2(4.4)$ & $14(45.2)$ & $2(6.5)$ \\
\hline Lymphopenia & 0 & 0 & $5(16.1)$ & $3(9.7)$ \\
\hline $\begin{array}{l}\text { Gastrointestinal } \\
\text { hemorrhage }\end{array}$ & $7(15.6)$ & $2(4.4)$ & $11(35.5)$ & $1(3.2)$ \\
\hline Dyspnoea & 0 & 0 & $6(19.4)$ & 0 \\
\hline Radiation dermatitis & 0 & 0 & $6(19.4)$ & 0 \\
\hline Cough & $2(4.4)$ & 0 & $4(12.9)$ & 0 \\
\hline Elevated TB & $10(22.2)$ & 0 & $8(25.8)$ & 0 \\
\hline Diarrhea & $6(13.3)$ & 0 & $9(29.0)$ & 0 \\
\hline Fatigue & $13(28.9)$ & 0 & $15(48.4)$ & 0 \\
\hline Hand-foot skin reaction & $9(20.0)$ & $2(4.4)$ & $7(22.6)$ & $1(3.2)$ \\
\hline Elevated creatinine & $2(4.4)$ & 0 & $2(6.5)$ & 0 \\
\hline Albuminuria/Proteinuria & $2(4.4)$ & 0 & $1(3.2)$ & 0 \\
\hline Decreased appetite & $4(8.9)$ & 0 & $4(12.9)$ & 0 \\
\hline Constipation & $1(2.2)$ & 0 & 0 & 0 \\
\hline Infusion-related reaction & $11(24.4)$ & 0 & $9(29.0)$ & 0 \\
\hline
\end{tabular}

\section{Discussion}

In this study, we report for the first time the efficacy of SBRT in patients with PD-1 inhibitor-TACE refractory intermediate-stage HCC. The results showed that switching to receive SBRT combined with PD- 
1 inhibitors provided better long-term prognosis and tumor control than continued receive TACE combined with PD-1 inhibitors. This provides more options for the treatment of patients with BCLC stage B HCC.

TACE is the standard of care for patients with BCLC stage B HCC[6-9], but some patients develop TACE refractoriness and cannot achieve effective tumor control[10, 11]. Guidelines recommend that patients start receiving systemic therapy once they are diagnosed as TACE refractoriness[6, 8, 9]. Currently, the most commonly used drugs for systemic therapy include targeted anti-vascular agents such as sorafenib and lenvatinib. The results of several phase III trials suggest that TACE combined with sorafenib does not improve the long-term prognosis of patients[22-26], whereas the recent Japanese TACTICS trial demonstrated that sorafenib was able to prolong PFS of patients [27], while a large number of retrospective studies proved that the combination therapy of targeted anti-vascular agents and TACE was potentially beneficial for HCC patients[20, 28-32]. Although the efficacy of TACE combined with targeted anti-vascular agents is still controversial, the therapeutic modality of TACE combined with systemic therapy has exhibited its promise[33]. Meanwhile, PD-1 inhibitors have been increasingly investigated as representative agents for immunotherapy. And the possible mechanism of benefit of TACE combined with PD-1 inhibitor was uncovered: TACE could decrease the ratio of CD4+ / CD8+ cells and increase the level of PD-1 mRNA expression in patients with HCC[12]. Therefore, TACE combined with PD-1 inhibitor might have potential clinical value for patients with HCC. This was precisely verified by the recent report by Chen et al., in which patients had increased PD-1 inhibitor treatment on the basis of TACE with improved oncological outcomes[14]. However, the role of PD-1 inhibitors for patients is also limited[34], and once a patient presents refractory to both PD- 1 inhibitors and TACE, what treatment should be followed up, which is a question worth exploring and urgently resolving.

Radiotherapy because the stronger hepatotoxicity limits its application, with the advancement of technology, SBRT is currently able to safely deliver high-dose radiotherapy to HCC, and the AASLD guidelines accepted SBRT as one of the treatments for HCC[7]. For patients with BCLC stage B HCC who received SBRT, the 2-year local control rate reached $61-81 \%[35]$. Several retrospective controlled studies containing patients with intermediate stage HCC showed that SBRT had similar or even higher tumor control rates and OS than TACE[18, 19]. On the one hand, a clinical trial demonstrated the safety and feasibility of SBRT as a local salvage regimen for incomplete TACE[36]. Radiotherapy can trigger immunogenic cell death (ICD), resulting in the release of cytokines and damage associated molecular patterns (DAMPs). DAMPs can lead to the subsequent priming and trafficking of tumor specific $T$ lymphocytes into the tumor microenvironment (TME) by enhancing the recruitment of antigen-presenting cells (APCs), the processing of tumor associated antigens (TAAs), and the cross presentation of antigenic peptides on major histocompatibility complex class I (MHC I), thereby enhancing the efficacy of PD-1 inhibitors[37]. And its clinical benefits have also been reported[36, 38, 39]. Therefore, we speculate that SBRT combined with PD-1 inhibitor may be a potential effective alternative treatment for patients who are refractory to PD-1 combined TACE.

Our results validate the above theory and suggest that this therapy of SBRT combined with PD-1 inhibitor can significantly improve the oncological outcomes of patients who are refractory to PD- 1 inhibitor

Page $11 / 18$ 
combined with TACE. In this study that enrolled 76 patients proven to be refractory to PD- 1 inhibitor TACE treatment, the SBRT group $(n=31)$ had a median PFS of 19.6 months $(95 \% \mathrm{Cl} 13.1-26.1)$, which was significantly higher than the TACE group $(n=45)$ with a median PFS of 10.1 months $(95 \%$ Cl 7.3-12.9, $P<$ 0.001). The 1-year OS rate and 1-year PFS rate in the SBRT group were $71.5 \%$ and $64.8 \%$, and the ORR and DCR were $71.0 \%$ and $80.6 \%$, respectively. The 1-year OS rate and 1-year PFS rate in the TACE group were $54.2 \%$ and $40.7 \%$, and the ORR and DCR were $15.6 \%$ and $31.1 \%$, respectively. Compared with TACE, SBRT significantly prolonged PFS $(\mathrm{HR}=0.361,95 \% \mathrm{Cl} 0.182-0.716, \mathrm{P}<0.01)$ and $\mathrm{OS}(\mathrm{HR}=0.375,95 \% \mathrm{Cl}$ 0.182-0.773, $\mathrm{P}<0.001)$, with better ORR $(\mathrm{OR}=8.483,95 \% \mathrm{Cl} 3.319-21.680, \mathrm{P}<0.001)$ and $\mathrm{DCR}(\mathrm{OR}=9.226$, $95 \% \mathrm{Cl} 3.096-27.493, \mathrm{P}<0.001)$ in PD-1 inhibitor-TACE refractory patients. In addition to efficacy, we analyzed TRAEs associated with SBRT plus PD-1 inhibitors. The most common TRAEs were increased AST (51.6\%), fatigue (48.4\%), and decreased platelet count (48.4\%). The most common grade 3/4 TRAEs were lymphopenia (9.7\%) and dysphagia (6.5\%). This is close to previous reports[40], with no unexpected TRAEs present. Therefore, SBRT combined with PD-1 is an effective and safe treatment modality for patients with PD-1 inhibitor-TACE refractory intermediate-stage HCC.

This study has several limitations. First, this is a retrospective study with inherent defects. Second, the sample size included in this study was small with potential selection bias. Third, there was some heterogeneity in patient populations and treatment regimens, which may have affected our findings. A prospective study is therefore needed to confirm our conclusions.

In conclusion, switching to receive SBRT was effective as evidenced by an increase in PFS and OS in patients with PD-1 inhibitor-TACE refractory intermediate-stage HCC. To improve the survival of those patients, it is important to switch treatment from TACE to SBRT even if the tumor is still in the intermediate stage.

\section{Declarations}

\section{Data Availability}

Raw data can be provided on request by the Editor.

\section{Author Contribution}

Conception and Design: Shu-Qun Cheng, Yun-Feng Shan, Yan-Jun Xiang

Financial Support: Shu-Qun Cheng, Kang Wang, Yun-Feng Shan

Provision of Study Materials or Patients: Yun-Feng Shan, Kang Wang, Shuang Feng, Xi Cheng, Hong-Ming Yu, Xiao-Wei Li, Ying-Yi Qin, Li-Ping Zhou, Jian Zhai, Yan Meng

Collection and Assembly of Data: Yan-Jun Xiang, Kang Wang, Yi-Tao Zheng, Shuang Feng, Hong-Ming Yu, Yu-Qiang Cheng, Wei-Jun Wang 
Data Analysis and Interpretation: Yan-Jun Xiang, Kang Wang, Yi-Tao Zheng, Shuang Feng, Ying-Yi Qin, Yun-Feng Shan, Shu-Qun Cheng

Manuscript Writing: All authors

Final Approval of Manuscript: All authors

\section{Conflict of Interest}

The authors declare that the research was conducted in the absence of any commercial or financial relationships that could be construed as a potential conflict of interest.

\section{Funding}

This work was supported by the Clinical Research Plan of SHDC (No. SHDC2020CR1004A), the State Key Program of National Natural Science Foundation of China (No: 81730097), the National Natural Science Foundation of China (No: 82072618 and No:81770630) and the Science and Technology Commission Foundation of Shanghai Municipality (No: 19411967300).

\section{Ethics approval}

This study was in compliance with the ethical standards of Declaration of Helsinki, and was approved by the Institutional Ethics Committees of the Eastern Hepatobiliary Surgery Hospital (EHBHKY2021-K-020) of the main center.

\section{Consent to Participate}

As patients' identities were anonymized, the requirement for informed consent was waived by the Ethics Committees.

\section{Animal Research (Ethics)}

Not applicable

\section{Consent to Publish (Ethics)}

Not applicable

\section{Plant Reproducibility}

Not applicable

\section{Clinical Trials Registration}

Not applicable 


\section{References}

1. Bray F, Ferlay J, Soerjomataram I, Siegel RL, Torre LA, Jemal A. Global cancer statistics 2018: GLOBOCAN estimates of incidence and mortality worldwide for 36 cancers in 185 countries. CA Cancer J Clin. 2018;68(6):394-424.

2. Bruix J, Sherman M. American Association for the Study of Liver D: Management of hepatocellular carcinoma: an update. Hepatology. 2011;53(3):1020-2.

3. European Association For The Study Of The. European Organisation For L, Treatment Of R. C: EASLEORTC clinical practice guidelines: management of hepatocellular carcinoma. J Hepatol 2012, 56(4):908-43.

4. Forner A, Reig M, Bruix J. Hepatocellular carcinoma. Lancet. 2018;391(10127):1301-14.

5. Bruix J, Reig M, Sherman M. Evidence-Based Diagnosis, Staging, and Treatment of Patients With Hepatocellular Carcinoma. Gastroenterology. 2016;150(4):835-53.

6. European Association for the Study of the Liver. Electronic address eee, European Association for the Study of the L: EASL Clinical Practice Guidelines: Management of hepatocellular carcinoma. J Hepatol. 2018;69(1):182-236.

7. Marrero JA, Kulik LM, Sirlin CB, Zhu AX, Finn RS, Abecassis MM, Roberts LR, Heimbach JK. Diagnosis, Staging, and Management of Hepatocellular Carcinoma: 2018 Practice Guidance by the American Association for the Study of Liver Diseases. Hepatology. 2018;68(2):723-50.

8. Vogel A, Cervantes A, Chau I, Daniele B, Llovet JM, Meyer T, Nault JC, Neumann U, Ricke J, Sangro B, et al. Hepatocellular carcinoma: ESMO Clinical Practice Guidelines for diagnosis, treatment and follow-up. Ann Oncol. 2018;29(Suppl 4):iv238-55.

9. Omata M, Cheng AL, Kokudo N, Kudo M, Lee JM, Jia J, Tateishi R, Han KH, Chawla YK, Shiina S, et al. Asia-Pacific clinical practice guidelines on the management of hepatocellular carcinoma: a 2017 update. Hepatol Int. 2017;11(4):317-70.

10. Kim HY, Park JW, Joo J, Jung SJ, An S, Woo SM, Kim HB, Koh YH, Lee WJ, Kim CM. Severity and timing of progression predict refractoriness to transarterial chemoembolization in hepatocellular carcinoma. J Gastroenterol Hepatol. 2012;27(6):1051-6.

11. Arizumi T, Minami T, Chishina H, Kono M, Takita M, Yada N, Hagiwara S, Minami Y, Ida H, Ueshima K, et al. Time to Transcatheter Arterial Chemoembolization Refractoriness in Patients with Hepatocellular Carcinoma in Kinki Criteria Stages B1 and B2. Dig Dis. 2017;35(6):589-97.

12. Guo J, Wang S, Han Y, Jia Z, Wang R. Effects of transarterial chemoembolization on the immunological function of patients with hepatocellular carcinoma. Oncol Lett. 2021;22(1):554.

13. Hiroishi K, Eguchi J, Baba T, Shimazaki T, Ishii S, Hiraide A, Sakaki M, Doi H, Uozumi S, Omori R, et al. Strong CD8(+) T-cell responses against tumor-associated antigens prolong the recurrence-free interval after tumor treatment in patients with hepatocellular carcinoma. J Gastroenterol. 2010;45(4):451-8. 
14. Chen S, Wu Z, Shi F, Mai Q, Wang L, Wang F, Zhuang W, Chen X, Chen H, Xu B, et al: Lenvatinib plus TACE with or without pembrolizumab for the treatment of initially unresectable hepatocellular
carcinoma harbouring PD-L1 expression: a retrospective study. J Cancer Res Clin Oncol 2021.

15. Bujold A, Massey CA, Kim JJ, Brierley J, Cho C, Wong RK, Dinniwell RE, Kassam Z, Ringash J, Cummings $B$, et al. Sequential phase I and II trials of stereotactic body radiotherapy for locally advanced hepatocellular carcinoma. J Clin Oncol. 2013;31(13):1631-9.

16. Liu E, Stenmark MH, Schipper MJ, Balter JM, Kessler ML, Caoili EM, Lee OE, Ben-Josef E, Lawrence TS, Feng M. Stereotactic body radiation therapy for primary and metastatic liver tumors. Transl Oncol. 2013;6(4):442-6.

17. Wahl DR, Stenmark MH, Tao Y, Pollom EL, Caoili EM, Lawrence TS, Schipper MJ, Feng M. Outcomes After Stereotactic Body Radiotherapy or Radiofrequency Ablation for Hepatocellular Carcinoma. J Clin Oncol. 2016;34(5):452-9.

18. Sapir E, Tao Y, Schipper MJ, Bazzi L, Novelli PM, Devlin P, Owen D, Cuneo KC, Lawrence TS, Parikh ND, et al. Stereotactic Body Radiation Therapy as an Alternative to Transarterial Chemoembolization for Hepatocellular Carcinoma. Int J Radiat Oncol Biol Phys. 2018;100(1):122-30.

19. Shen PC, Chang WC, Lo CH, Yang JF, Lee MS, Dai YH, Lin CS, Fan CY, Huang WY. Comparison of Stereotactic Body Radiation Therapy and Transarterial Chemoembolization for Unresectable Medium-Sized Hepatocellular Carcinoma. Int J Radiat Oncol Biol Phys. 2019;105(2):307-18.

20. Fu Z, Li X, Zhong J, Chen X, Cao K, Ding N, Liu L, Zhang X, Zhai J, Qu Z. Lenvatinib in combination with transarterial chemoembolization for treatment of unresectable hepatocellular carcinoma (uHCC): a retrospective controlled study. Hepatol Int. 2021;15(3):663-75.

21. Benedict SH, Yenice KM, Followill D, Galvin JM, Hinson W, Kavanagh B, Keall P, Lovelock M, Meeks S, Papiez L, et al. Stereotactic body radiation therapy: the report of AAPM Task Group 101. Med Phys. 2010;37(8):4078-101.

22. Kudo M, Imanaka K, Chida N, Nakachi K, Tak WY, Takayama T, Yoon JH, Hori T, Kumada H, Hayashi $\mathrm{N}$, et al. Phase III study of sorafenib after transarterial chemoembolisation in Japanese and Korean patients with unresectable hepatocellular carcinoma. Eur J Cancer. 2011;47(14):2117-27.

23. Park JW, Kim YJ, Kim DY, Bae SH, Paik SW, Lee YJ, Kim HY, Lee HC, Han SY, Cheong JY, et al. Sorafenib with or without concurrent transarterial chemoembolization in patients with advanced hepatocellular carcinoma: The phase III STAH trial. J Hepatol. 2019;70(4):684-91.

24. Meyer T, Fox R, Ma YT, Ross PJ, James MW, Sturgess R, Stubbs C, Stocken DD, Wall L, Watkinson A, et al. Sorafenib in combination with transarterial chemoembolisation in patients with unresectable hepatocellular carcinoma (TACE 2): a randomised placebo-controlled, double-blind, phase 3 trial. Lancet Gastroenterol Hepatol. 2017;2(8):565-75.

25. Lencioni R, Llovet JM, Han G, Tak WY, Yang J, Guglielmi A, Paik SW, Reig M, Kim DY, Chau GY, et al. Sorafenib or placebo plus TACE with doxorubicin-eluting beads for intermediate stage HCC: The SPACE trial. J Hepatol. 2016;64(5):1090-8. 
26. Kudo M, Han G, Finn RS, Poon RT, Blanc JF, Yan L, Yang J, Lu L, Tak WY, Yu X, et al. Brivanib as adjuvant therapy to transarterial chemoembolization in patients with hepatocellular carcinoma: $A$ randomized phase III trial. Hepatology. 2014;60(5):1697-707.

27. Kudo M, Ueshima K, Ikeda M, Torimura T, Tanabe N, Aikata H, Izumi N, Yamasaki T, Nojiri S, Hino K, et al. Randomised, multicentre prospective trial of transarterial chemoembolisation (TACE) plus sorafenib as compared with TACE alone in patients with hepatocellular carcinoma: TACTICS trial. Gut. 2020;69(8):1492-501.

28. Ren B, Wang W, Shen J, Li W, Ni C, Zhu X. Transarterial Chemoembolization (TACE) Combined with Sorafenib versus TACE Alone for Unresectable Hepatocellular Carcinoma: A Propensity Score Matching Study. J Cancer. 2019;10(5):1189-96.

29. Cabrera R, Pannu DS, Caridi J, Firpi RJ, Soldevila-Pico C, Morelli G, Clark V, Suman A, George TJ Jr, Nelson DR. The combination of sorafenib with transarterial chemoembolisation for hepatocellular carcinoma. Aliment Pharmacol Ther. 2011;34(2):205-13.

30. Cheng Z, He L, Guo Y, Song Y, Song S, Zhang L. The combination therapy of transarterial chemoembolisation and sorafenib is the preferred palliative treatment for advanced hepatocellular carcinoma patients: a meta-analysis. World J Surg Oncol. 2020;18(1):243.

31. Li L, Zhao W, Wang M, Hu J, Wang E, Zhao Y, Liu L. Transarterial chemoembolization plus sorafenib for the management of unresectable hepatocellular carcinoma: a systematic review and metaanalysis. BMC Gastroenterol. 2018;18(1):138.

32. Zhang X, Wang K, Wang M, Yang G, Ye X, Wu M, Cheng S. Transarterial chemoembolization (TACE) combined with sorafenib versus TACE for hepatocellular carcinoma with portal vein tumor thrombus: a systematic review and meta-analysis. Oncotarget. 2017;8(17):29416-27.

33. Llovet JM, De Baere T, Kulik L, Haber PK, Greten TF, Meyer T, Lencioni R. Locoregional therapies in the era of molecular and immune treatments for hepatocellular carcinoma. Nature Reviews Gastroenterology Hepatology. 2021;18(5):293-313.

34. Kudo M. Limited Impact of Anti-PD-1/PD-L1 Monotherapy for Hepatocellular Carcinoma. Liver Cancer. 2020;9(6):629-39.

35. Bang A, Dawson LA. Radiotherapy for HCC: Ready for prime time? JHEP Rep. 2019;1(2):131-7.

36. Kang JK, Kim MS, Cho CK, Yang KM, Yoo HJ, Kim JH, Bae SH, Jung DH, Kim KB, Lee DH, et al. Stereotactic body radiation therapy for inoperable hepatocellular carcinoma as a local salvage treatment after incomplete transarterial chemoembolization. Cancer. 2012;118(21):5424-31.

37. Romano E, Honeychurch J, Illidge TM. Radiotherapy-Immunotherapy Combination: How Will We Bridge the Gap Between Pre-Clinical Promise and Effective Clinical Delivery? Cancers (Basel) 2021, 13(3).

38. Chiang CL, Chan ACY, Chiu KWH, Kong FS. Combined Stereotactic Body Radiotherapy and Checkpoint Inhibition in Unresectable Hepatocellular Carcinoma: A Potential Synergistic Treatment Strategy. Front Oncol. 2019;9:1157. 
39. Zhong L, Wu D, Peng W, Sheng H, Xiao Y, Zhang X, Wang Y. Safety of PD-1/PD-L1 Inhibitors Combined With Palliative Radiotherapy and Anti-Angiogenic Therapy in Advanced Hepatocellular Carcinoma. Front Oncol. 2021;11:686621.

40. Zhou X, Yao Z, Bai H, Duan J, Wang Z, Wang X, Zhang X, Xu J, Fei K, Zhang Z, et al: Treatment-related adverse events of PD-1 and PD-L1 inhibitor-based combination therapies in clinical trials: a systematic review and meta-analysis. The Lancet Oncology 2021.

\section{Figures}

Patients with BCLC stage B HCC who were treated with TACE and PD-1 inhibitors were recruited from the Eastern Hepatobiliary Surgery Hospital and the First Affiliated Hospital of Wenzhou Medical University from 2019 to $2020(n=256)$

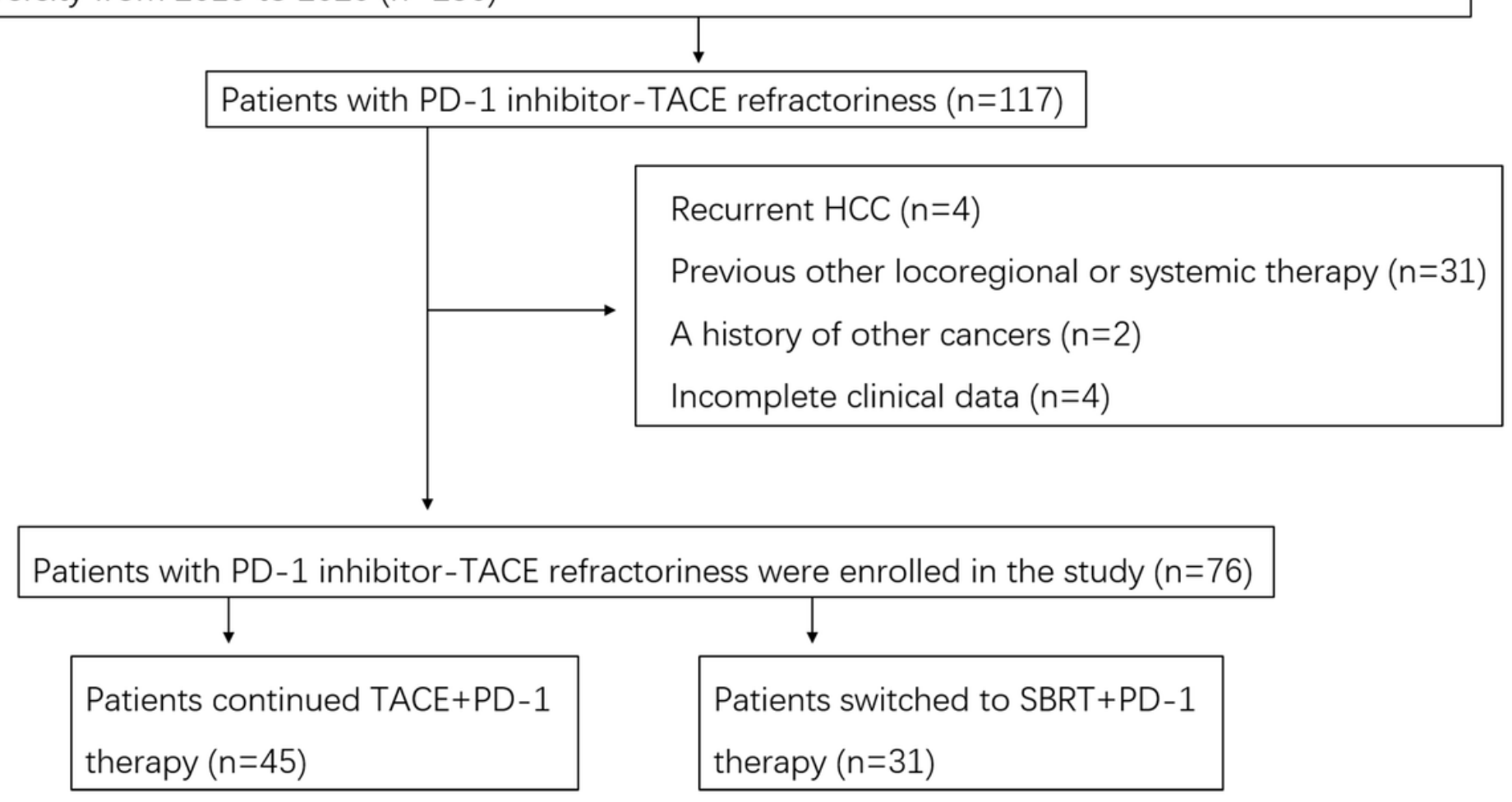

\section{Figure 1}

Flow diagram for the present study BCLC, Barcelona Clinic Liver Cancer; HCC, hepatocellular carcinoma; TACE, transarterial chemoembolization; SBRT, stereotactic body radiation therapy. 
A

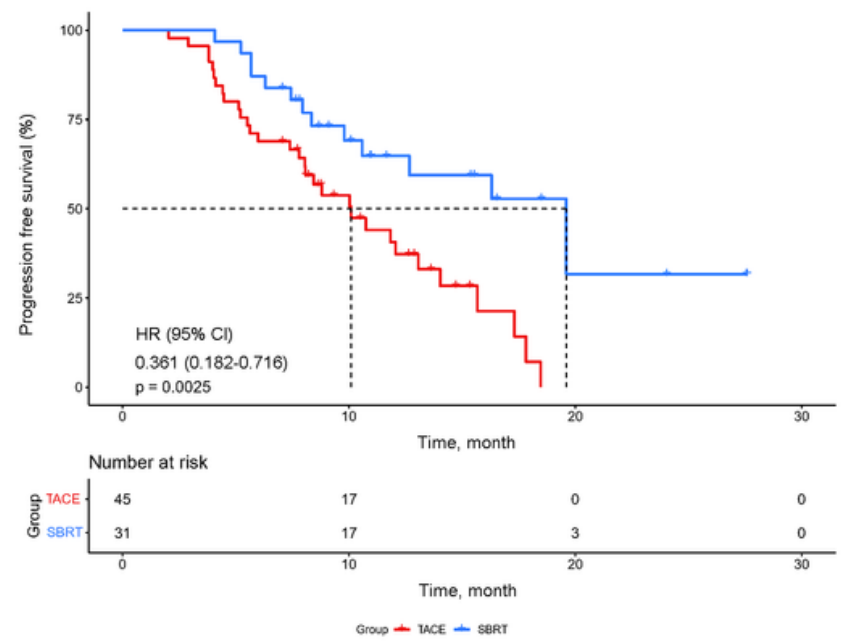

B
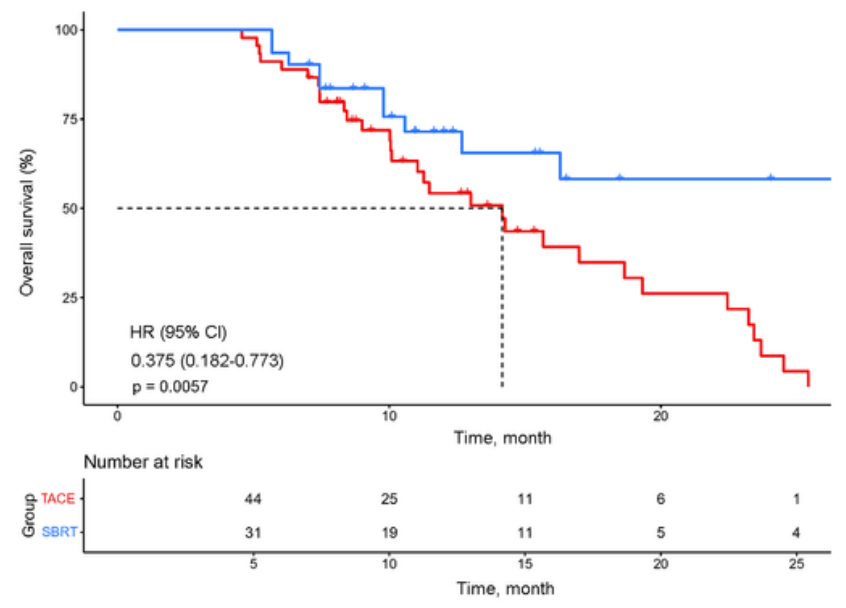

Figure 2

Kaplan-Meier estimated PFS and OS curves in HCC patients with different therapies. (A) PFS; (B) OS. PFS, progression free survival; OS, overall survival; HCC, hepatocellular carcinoma; TACE, transarterial chemoembolization; SBRT, stereotactic body radiation therapy.

\section{Supplementary Files}

This is a list of supplementary files associated with this preprint. Click to download.

- SupplementaryTable1.docx 